\title{
Effect of tranexamic acid on symptomatic venous thromboembolism in patients undergoing primary total knee arthroplasty
}

\author{
Huiming Peng, Longchao Wang, Xisheng Weng, Jiliang Zhai, Jin Lin, Jin Jin, Wenwei Qian, Na Gao
}

Department of Orthopedics, Peking Union Medical College Hospital, Chinese Academy of Medical Sciences and Peking Union Medical College, Beijing, China

Submitted: 23 June 2017

Accepted: 17 August 2017

Arch Med Sci 2020; 16 (3): 603-612

DOI: https://doi.org/10.5114/aoms.2020.92444

Copyright (c) 2019 Termedia \& Banach

\section{Abstract}

Introduction: This study aimed to investigate the effect of tranexamic acid (TXA) with sequential routine anticoagulation on postoperative symptomatic venous thromboembolism (VTE) in patients undergoing primary total knee arthroplasty (TKA).

Material and methods: This was a prospective study with randomized trials. From January 2013 to May 2015, 1880 patients undergoing primary TKA were enrolled in this study. Seven hundred and twenty patients who received TXA injection were included in the TXA group while 1160 patients who received placebo injection were included in the control group. Patients in the TXA group were treated with intravenous TXA or topical intravenous TXA, and all received sequential routine anticoagulation $12 \mathrm{~h}$ after the operation. We extracted data of patients' sex, age, primary diagnoses, and comorbidities that could potentially affect the prevalence rate of VTE. To discuss the risk factors of symbolic VTE, comparisons were made within the TXA group between patients with symbolic VTE and non-symbolic VTE. Logistic regression analysis was performed to analyze the concurrent effects of various factors on the prevalence rate of postoperative VTE.

Results: Thigh perimeter was not closely associated with TXA injection. Within the TXA group, 24 (3.3\%) patients had perioperative symptomatic VTE, $16(2.2 \%)$ deep vein thrombosis (DVT) and 8 (1.1\%) pulmonary embolism. High body mass index (BMI), low fibrinogen (Fbg) and simultaneous bilateral TKA were significant risk factors in both univariate analysis and multivariate analysis.

Conclusions: Increased BMI, low Fbg, and simultaneous bilateral TKA could act as risk factors for postoperative symptomatic VTE treated with TXA.

Key words: total knee arthroplasty, tranexamic acid, venous thromboembolism, risk factors.

\section{Introduction}

Total knee arthroplasty (TKA), one of the most common curative operations for end-stage arthritis of the knee, can effectively relieve pain, improve the knee function, and improve the quality of patients' life [1-3]. In the United States, there are over 600,000 TKAs and over 285,000 total hip arthroplasties (THAs) performed every year [4]. The demand for primary TKA is predicted to grow by $673 \%$, to reach 3.48 million by 2030 in the United States. Although the operation has

\author{
Corresponding author: \\ Xisheng Weng \\ Department of Orthopedics \\ Peking Union \\ Medical College Hospital \\ Chinese Academy \\ of Medical Sciences \\ and Peking Union \\ Medical College \\ 1 Shuaifuyuan \\ Wangfujing \\ Dongcheng District \\ Beijiing 100730, China \\ Phone: +86 13366200018 \\ Fax: +86 1069152810 \\ E-mail: xishengweng@ \\ medmail.com.cn
}


good outcomes and is generally well tolerated, the complications of blood transfusion are also severe, including infection, transfusion-related liver damage, hemolysis, immune suppression, prolonged rehabilitation duration and allergic reactions [5], and blood loss is a major concern both during and after TKA surgery [6].

In western countries, venous thromboembolism (VTE) is composed of pulmonary embolism (PE) and deep venous thrombosis (DVT), and it has been identified as a significant public health concern [7, 8]. Undergoing THA and TKA could significantly increase the risk of VTE, whose prevalence rate was estimated as $60 \%$ without appropriate prophylaxis [9]. Venous thromboembolism is also a major contributor to morbidity and mortality among orthopedic patients and body mass index (BMI) could be correlated with it [8] Mortality rates from VTE following lower limb arthroplasty are low. It was estimated that before 1980 , the VTE prevalence rate without prophylaxis was about $15-30 \%$, but it has been reduced to $1-2 \%$ after the contemporary prophylactic strategies were applied in 2001 [10]. Now, even though the administered drug remained controversial, the western guidelines have strongly recommended routine chemoprophylaxis to reduce the incidence of VTE for patients who underwent TKA [11].

Tranexamic acid (TXA) is an analog of lysine that can reduce blood transfusion and loss, and it can efficiently inhibit fibrinolysis through hindering plasmin's binding to fibrin and activation of plasminogen $[2,12,13]$. Tranexamic acid has been applied widely in cardiac surgery, tonsillectomy, spinal surgery, hemophilia, gynecological surgery and oral surgery [14]. It has also been shown that TXA can significantly reduce blood loss and transfusion rates after TKA without increasing the incidence of VTE [15]. As reported by recent meta-analyses, the effect of intravenous (IV) TXA on blood loss was estimated to be up to around $600 \mathrm{ml}$ for TKA [1618]. Tranexamic acid (TXA) elicits an anti-fibrinolytic effect; in theory, TXA can be used to reduce blood loss in TKA. European and U.S. studies on this topic have shown that the intravenous administration of TXA can significantly reduce post-operative blood loss and the need for transfusion. However, limited information has been presented regarding the effectiveness and safety of TXA for Chinese patients subjected to TKA [19].

Although IV TXA has been well proved to be safe for healthy people, it was still unclear if this held true for patients with a history of VTE. It has been discredited that TXA acts as a procoagulant, and it had antithrombotic effects [20]. However, whether TXA had positive effects on VTE after TKA was still not well-defined, which was restrict- ed by the small sample size. Thus, our study was designed to explore the effects of using TXA after first TKA surgery on the incidence rates of VTE, and analyze risk factors that affect the incidence of symptomatic VTE.

\section{Material and methods}

\section{Patients' characteristics}

Prior to this trial, approval from the Institutional Ethics Committee of Peking Union Medical College Hospital was obtained. Additionally, written informed consent and research authorizations were obtained prospectively prior to surgery. From January 2013 to May 2015, multiple TKA cases involving 1880 patients were included in this study and randomized to the experimental group and control group. Inclusion criteria: (i) all the patients were undergoing primary TKA; (ii) the patients were over 18 years old; (iii) patients who received TXA injection were in the perioperative period; (iv) patients underwent a standardized VTE prophylactic anticoagulant therapy postoperatively; (v) all patients included had given written consent. Exclusion criteria: (i) patients had a history of venous thromboembolism, pulmonary embolism and coronary heart disease; (ii) patients had coagulopathy; (iii) oral non-steroidal anti-inflammatory drugs (NSAIDs) were discontinued for less than 1 week; (iv) patients were clearly allergic to TXA; (v) patients had severe liver and kidney dysfunctions; (vi) patients had high risk of thrombosis. In the end, a total of 720 cases (878 knees) were included in the TXA group, including 562 unilateral TKA cases and 158 bilateral TKA cases. Among them, there were 658 cases with primary osteoarthritis and 53 cases with rheumatoid arthritis.

\section{Operation}

Procedures were completed by four senior orthopedic surgeons for objectivity and reliability of experiments in this randomized comparison study (RCT). Patients randomized to the experimental group used TXA injection while those in the control group received placebo injection. The surgical techniques and procedures applied were up to date. Prophylactic intravenous antibiotics were given to all patients $30 \mathrm{~min}$ before the surgery. During the operation, medial parapatellar arthrotomy as the standard approach of exposure of the knee joint allowed adequate exposure for TKA. Then, anterior midline incision, the most commonly used skin incision for primary TKA, and a utilitarian extensile approach to the knee were done with the knee in flexion to allow the subcutaneous tissue to fall medially and laterally, improving exposure and obvi- 
ating the need for raising skin flaps [21]. After the surgery, all patients used the posterior stabilized prosthesis and were fixed with bone cement. The tourniquet was not released until skin closure. A 16 gauge drainage tube was placed, and was opened after 3 to $4 \mathrm{~h}$ of postoperative clamping. Residual volume of the tube was less than $200 \mathrm{ml}$ within $24 \mathrm{~h}$, so the catheter/tube was then removed [22].

\section{Evaluation and diagnosis of venous thromboembolism}

Deep vein thrombosis was assessed before performing TKA. Patients were assessed with the Wells score to determine whether there was obvious swelling of the lower limbs (greater than the preoperative value of $3 \mathrm{~cm}$ ), pain or Homan positiveness and usage of Doppler ultrasonography for investigating DVT. Variate scores indicate different probability of DVT diagnosis. A score < 2.0 means low probability, 2.0-6.0 means mediate probability, while $>6.0$ indicates high probability. Diagnostic criteria: (i) venous lumen could not be closed; (ii) the cavity was hypoechoic or echoless; (iii) there was no or only a small amount of blood flow signal within venous thrombosis; (iv) the pulse of Doppler showed no blood flow or the spectrum did not change with respiration. If chest pain and chest tightness occur, patients should be immediately tested for pulmonary embolism with a CT pulmonary angiogram (CTPA).

\section{Basic precautions}

The process of TKA should be gentle and delicate to avoid intravenous intimal injury. The limb was raised to prevent deep venous reflux disorder or blood would not successfully flow around the body. Patients were encouraged to stand up, to perform early functional exercise, to get out of bed, to take deep breaths and to cough. The patients were suggested to drink more water, so that dehydration could be avoided.

\section{Physical and drug prophylactic anticoagulation}

An intermittent pneumatic foot vein pump and stretch socks were used. The patients were subcutaneously given enoxaparin sodium (Clexane, Sanofi Aventis) or orally given rivaroxaban (Xarelto, Bayer). In the first stage, enoxaparin sodium was given once a day, and the dosage was adjusted according to the patients' weight. Some of the patients were subcutaneously given conventional doses (i.e. low-molecular-weight heparin) $12-24 \mathrm{~h}$ after TKA surgery (2-4 h after epidural catheter removal), and some were giv- en half of the conventional doses 4-6 $\mathrm{h}$ after surgery, and the next day conventional doses were given. This process was generally repeated once every $24 \mathrm{~h}$ for 3-5 days. In the second stage, subcutaneous injection of low molecular weight heparin or oral administration of warfarin 10 mg once a day was used for 10-14 days after surgery.

\section{Methods of using tranexamic acid}

The use of TXA was mainly divided into two types: (i) $15 \mathrm{mg} / \mathrm{kg}$ TXA was intravenously injected in $15 \mathrm{~min}$ before release of the tourniquet; (ii) $15 \mathrm{mg} / \mathrm{kg}$ TXA with $1 \mathrm{~g} / 50 \mathrm{ml}$ TXA topical application was intravenously injected before tourniquet release.

\section{Risk factors of symptomatic venous thromboembolism}

The risk factors were selected based on the following: (i) relevant factors in the literature report; (ii) experience and accumulation in clinical work; (iii) factors that may be relevant but pending confirmation; (iv) indicators that were relatively independent, or may have certain relevance, but without a direct causal relationship. Thus, patients' related factors were applied, including gender, age, BMI, diagnosis, personal history (i.e. history of smoking and alcohol consumption), comorbidities (i.e. hypertension, diabetes, cerebrovascular disease, malignancy history, arrhythmia) and American Anesthesiologists Association (ASA) score; patients classified as III and above are considered not qualified for an anesthesia. Preoperative laboratory tests were reviewed, including hematocrit (Hct), hemoglobin ( $\mathrm{Hgb})$, platelet count (Plt), prothrombin time (PT), international normalized ratio (INR), activated partial thrombin time (APTT), fibrinogen (Fbg) and D-dimer. Preoperative medication history was recorded, including aspirin and lipid-lowering agents. Operation-related factors were also described, including the surgeons (i.e. $A, B, C, D$ ), anesthesia, surgery (i.e. unilateral TKA and one-stage bilateral TKA), usage of tourniquet, and placement of drainage after operation.

\section{Statistical analysis}

All indicators were analyzed with SPSS 21.0 software (IBM, USA). Count data were presented as percentages, and measurement data were presented as mean and standard deviation. The risk factors for symptomatic VTE were analyzed by single factor analysis (i.e. $\chi^{2}$ test and independent sample $t$-test) and the multivariate logistic regression test. $P<0.05$ was considered to indicate statistical significance. 
Huiming Peng, Longchao Wang, Xisheng Weng, Jiliang Zhai, Jin Lin, Jin Jin, Wenwei Qian, Na Gao

Table I. Baseline characteristics of subjects treated with traditional schemes and tranexamic acid

\begin{tabular}{|c|c|c|c|c|}
\hline Indicators & Controls & Tranexamic acid & $\chi^{2} / t$ & $P$-value \\
\hline Number & 1160 & 720 & & \\
\hline Age, mean \pm SD [years] & $68.4 \pm 8.93$ & $66.47 \pm 7.64$ & 0.168 & 0.868 \\
\hline \multicolumn{5}{|l|}{ Gender, $n(\%)$ : } \\
\hline Male & $184(15.86)$ & $176(24.44)$ & 21.360 & $<0.001^{*}$ \\
\hline Female & $976(84.14)$ & $544(75.56)$ & & \\
\hline $\mathrm{BMI}\left[\mathrm{kg} / \mathrm{m}^{2}\right]:$ & $26.92 \pm 3.84$ & $26.74 \pm 4.08$ & -0.431 & 0.852 \\
\hline $\mathrm{BMI}<25$ & $431(37.16)$ & $253(35.14)$ & 0.780 & 0.502 \\
\hline $\mathrm{BMI} \geq 25$ & $729(62.84)$ & $467(64.86)$ & & \\
\hline \multicolumn{5}{|l|}{ Protopathy, $n(\%)$ : } \\
\hline Osteoarthritis & & $658(91.39)$ & & \\
\hline Rheumatoid arthritis & & $53(7.36)$ & & \\
\hline Others & & $9(1.25)$ & & \\
\hline \multicolumn{5}{|l|}{ Diagnosis, $n(\%)$ : } \\
\hline $\mathrm{OA}$ & $1067(91.98)$ & $658(91.39)$ & 0.207 & 0.667 \\
\hline Non-OA & $93(8.02)$ & $62(8.61)$ & & \\
\hline \multicolumn{5}{|l|}{ Surgery, $n(\%)$ : } \\
\hline Unilateral TKA & $817(70.43)$ & $562(78.06)$ & 13.312 & $<0.001^{*}$ \\
\hline Bilateral TKA & $343(29.57)$ & $158(21.94)$ & & \\
\hline \multicolumn{5}{|l|}{ Symptomatic VTE, $n(\%)$ : } \\
\hline Yes & $39(3.36)$ & $24(3.33)$ & 0.001 & 1.000 \\
\hline No & $1121(96.94)$ & $696(96.67)$ & & \\
\hline \multicolumn{5}{|l|}{ PE, $n(\%):$} \\
\hline Yes & $2(0.17)$ & $6(0.83)$ & 3.150 & 0.170 \\
\hline No & $1158(99.83)$ & $714(99.17)$ & & \\
\hline \multicolumn{5}{|l|}{ Near-end DVT, $n(\%)$ : } \\
\hline Yes & $6(0.51)$ & $6(0.83)$ & 0.290 & 0.821 \\
\hline No & $1154(99.49)$ & $714(99.17)$ & & \\
\hline
\end{tabular}

BMI - body mass index, OA - osteoarthritis, TKA - total knee arthroplasty, VTE - venous thromboembolism, PE - pulmonary embolism, DVT - deep vein thrombosis.

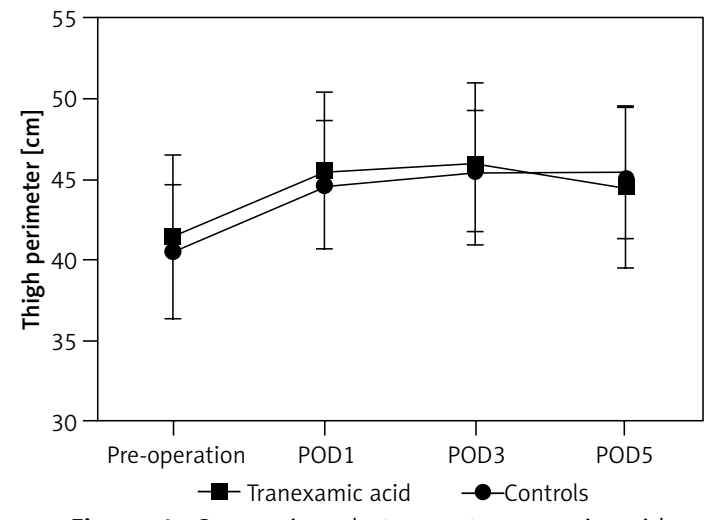

Figure 1. Comparison between tranexamic acid group and control group regarding thigh perimeter

\section{Results}

\section{Basic information of included patients}

A total of 1880 TKA patients were recruited; 720 of them received TXA injection while 1160 received placebo sodium chloride injection. There were significant differences in symptomatic VTE, indicating the effectiveness of TKA (Table I). No close association between thigh perimeter and TXA was found ( $p>0.05$, Figure 1). Tranexamic acid was found to be associated with adverse effects (Table II), which would possibly reduce the blood transfusion and blood loss. A total of 24 patients were found with symptomatic VTE, 
Table II. Indicators related to peri-operative blood of subjects treated with traditional schemes and tranexamic acid

\begin{tabular}{|c|c|c|c|c|}
\hline Indicators & Controls & Tranexamic acid & $\chi^{2} / t$ & $P$-value \\
\hline Number & 1160 & 720 & & \\
\hline \multicolumn{5}{|c|}{ Peri-operative blood transfusion, $n$ : } \\
\hline Unilateral & $312 / 817$ & $253 / 562$ & 2.666 & 0.103 \\
\hline Bilateral & $343 / 343$ & $158 / 158$ & 0 & 1 \\
\hline Total & 655 & 411 & 0.019 & 0.89 \\
\hline \multicolumn{5}{|c|}{ Total peri-operative blood loss, mean \pm SD $[\mathrm{ml}]$ : } \\
\hline Unilateral & $1064 \pm 78.7$ & $992 \pm 68.2$ & 20.27 & $<0.001$ \\
\hline Bilateral & $1682 \pm 63.5$ & $1564 \pm 93.6$ & 32.54 & $<0.001$ \\
\hline \multicolumn{5}{|c|}{ Peri-operative hidden blood loss, mean \pm SD [ml]: } \\
\hline Unilateral & $523 \pm 78.4$ & $505 \pm 62.8$ & 5.21 & $<0.001$ \\
\hline Bilateral & $765 \pm 86.0$ & $862 \pm 75.6$ & 24.88 & $<0.001$ \\
\hline
\end{tabular}

including $16(2.2 \%)$ patients of symptomatic DVT and $8(1.11 \%)$ cases of symptomatic PE. No deaths occurred 30 days after operation.

\section{Analysis of risk factors in patients with symptomatic venous thromboembolism}

Among 720 patients who received TXA, 24 had symptomatic VTE and 696 had other symptoms. Tables III-VI show the results of univariate analysis of perioperative TKA. The results show that $\mathrm{BMI}, \mathrm{Fbg}$, and surgical approach (i.e. unilateral TKA/a bilateral TKA) were significantly associated with symptomatic VTE $(p<0.05)$. On the other hand, diagnosis, personal history of smoking and alcohol, comorbidities (i.e. hypertension, diabetes, cerebrovascular disease, arrhythmia and hyperlipidemia), the number of complications, ASA score, preoperative test (i.e. hemoglobin, platelet, D-dimer, INR, PT, APTT), surgeons, anesthesia, drainage tube clamped or not, and the use of hemostatic zone showed no significant difference. Then, BMI (OR $=0.213$, 95\% Cl: 0.017-0.635, $p=0.006)$, Fbg $(\mathrm{OR}=2.550$, $95 \% \mathrm{Cl}: 1.803-6.003, p=0.032)$ and surgical type $(\mathrm{OR}=3.612,95 \% \mathrm{Cl}: 1.551-8.410, p=0.003)$ were analyzed by a multivariate logistic regression model, indicating that they still showed significant correlations with symptomatic VTE (Table VII). The risk of VTE in bilateral surgery was 3.612 times higher than that in the unilateral operation, and increasing Fbg would result in a 2.55 -fold increase in the risk of VTE (Table VII).

\section{Intervention and outcome of symptomatic venous thromboembolism patients}

All symptomatic VTE patients recovered. After definite diagnosis, low-molecular-weight heparin was subcutaneously injected from once a day to 2 times a day. After taking warfarin anticoagulation, patients were discharged as outpatients. The INR of prothrombin time for outpatient follow-up monitoring was maintained as 2-3 for 3 months. Dosage injection changed with different symptoms. Six PE patients were found without lower-limb swelling, pain symptoms or difficulty to correct hypoxemia. Thus, the dosage of low-molecular-weight heparin was changed from prevention to treatment, and oral warfarin anticoagulation was stopped and the patients discharged 2 weeks later. The INR of prothrombin time in outpatient follow-up monitoring was maintained as 2-3 for 3 months. No death occurred within 90 days after the operation.

\section{Discussion}

In order to decrease the risk of perioperative blood loss and transfusion, TXA has been extensively studied as an adjunct treatment for TKA [20]. However, TKA was one of the most highly risky procedures that would result in VTE $[20,23]$. Hence, we sought to determine whether the usage of TXA was associated with increased risk of VTE.

There have been a variety of studies that reported the risk of VTE after TKA. Bin Abd Razak et al. [24] reported that in 531 Asian patients who underwent unilateral TKAs without drug anticoagulation after surgery, only $4(0.75 \%)$ of them had symptomatic VTE, and 1 had symptomatic PE. However, in the meta-analysis by Januel et al., 44,844 cases of THA or TKA were included in 47 randomized clinical controls and observational studies [25]. All the subjects received anticoagulation to prevent VTE, showing that the total incidences of symptomatic VTE, DVT and PE after TKA were $1.09 \%, 0.63 \%$ and $0.27 \%$. 
Huiming Peng, Longchao Wang, Xisheng Weng, Jiliang Zhai, Jin Lin, Jin Jin, Wenwei Qian, Na Gao

Table III. Univariate analysis of baseline characteristics between venous thromboembolism (VTE) and non-VTE patients

\begin{tabular}{|c|c|c|c|c|c|c|c|c|}
\hline \multirow[t]{2}{*}{ Indicators } & \multicolumn{4}{|c|}{ TXA } & \multicolumn{4}{|c|}{ Placebo } \\
\hline & $\begin{array}{c}\text { Symptomatic } \\
\text { VTE }\end{array}$ & Non-VTE & $\chi^{2} / t$ & $P$-value & $\begin{array}{c}\text { Symptomatic } \\
\text { VTE }\end{array}$ & Non-VTE & $\chi^{2} / t$ & $P$-value \\
\hline Number & 24 & 696 & & & 39 & 1121 & & \\
\hline $\begin{array}{l}\text { Age, mean } \pm \text { SD } \\
\text { [years]: }\end{array}$ & $66.74 \pm 7.694$ & $66.46 \pm 8.937$ & 0.146 & 0.884 & $68.71 \pm 9.151$ & $68.37 \pm 8.454$ & 0.229 & 0.821 \\
\hline$<60$ & 7 & 131 & 2.245 & 0.325 & 7 & 184 & 0.798 & 0.671 \\
\hline $60-79$ & 17 & 542 & & & 27 & 836 & & \\
\hline$\geq 80$ & 0 & 23 & & & 5 & 101 & & \\
\hline \multicolumn{9}{|l|}{ Gender, $n$ : } \\
\hline Male & 9 & 166 & 2.305 & 0.129 & 10 & 174 & 2.892 & 0.140 \\
\hline Female & 15 & 530 & & & 29 & 947 & & \\
\hline Mean BMI $\left[\mathrm{kg} / \mathrm{m}^{2}\right]$ : & $26.75 \pm 3.80$ & $26.08 \pm 4.08$ & 0.793 & 0.428 & $27.19 \pm 3.62$ & $26.23 \pm 3.97$ & 1.489 & 0.137 \\
\hline $\mathrm{BMI}<25$ & 4 & 249 & 2.926 & 0.044 & 9 & 422 & 2.830 & 0.046 \\
\hline $\mathrm{BMI} \geq 25$ & 20 & 447 & & & 30 & 699 & & \\
\hline \multicolumn{9}{|l|}{ Diagnosis, $n$ : } \\
\hline OA & 22 & 636 & 0.132 & 0.717 & 36 & 1031 & 0.051 & 0.823 \\
\hline Non-OA & 2 & 60 & & & 3 & 90 & & \\
\hline \multicolumn{9}{|l|}{ Smoking history, $n$ : } \\
\hline Yes & 3 & 85 & 0.075 & 0.783 & 6 & 134 & 0.769 & 0.380 \\
\hline No & 21 & 611 & & & 33 & 987 & & \\
\hline \multicolumn{9}{|l|}{ Drinking history, $n$ : } \\
\hline Yes & 2 & 56 & 0.109 & 0.741 & 11 & 188 & 2.709 & 0.100 \\
\hline No & 22 & 640 & & & 28 & 933 & & \\
\hline \multicolumn{9}{|l|}{ ASA rating, $n$ : } \\
\hline $1-2$ & 22 & 645 & 0.025 & 0.876 & 34 & 999 & 0.014 & 0.904 \\
\hline 3 & 2 & 51 & & & 5 & 122 & & \\
\hline
\end{tabular}

$B M I$ - body mass index, OA - osteoarthritis, ASA - American Society of Anesthesiologists, TXA - tranexamic acid.

However, we found that conventional use of tranexamic acid sequential preventive anticoagulation after perioperative treatments made the incidence of symptomatic VTE $3.33 \%$, which was slightly higher than in the literature. Many clinical studies and several meta-analyses have confirmed that this way could effectively reduce the rates of blood loss and transfusion in TKA without increasing the risk of complications [6]. The distinction might be explained by the different diagnostic methods used, such as lower limb venography and lower extremity deep vein ultrasound, as well as the inconsistent observation time. The time with VTE risk is much longer than hospital stay, in Bin Abd Razak's research [24]. The average hospital stay was 5.2 days, during which the specialist was consulted to determine whether VTE occurred. Follow-up observations were practiced by assessing the swelling of the body to determine VTE. In Januel's research, the average length of follow-up was only 13 days. In this study, the average hospital stay was 18.4 days, and the observation time was even longer [25]. Also, symptomatic VTE was evaluated and diagnosed as comprehensive (independent of health care based on scoring system). With the Wells score for symptoms, the detection rate of VTE might increase.

Poeran et al. [26] conducted a retrospective study of 870,000 patients with complete hip/knee replacement for 6 consecutive years in 510 hospitals in the United States, finding that the incidence of deep venous thrombosis after using TXA was 
Table IV. Univariate analysis of preoperative laboratory and medication between venous thromboembolism (VTE) and non-VTE patients

\begin{tabular}{|c|c|c|c|c|c|c|c|c|}
\hline \multirow{2}{*}{ Indicators } & \multicolumn{4}{|c|}{ TXA } & \multicolumn{4}{|c|}{ Placebo } \\
\hline & $\begin{array}{c}\text { Symptomatic } \\
\text { VTE }\end{array}$ & Non-VTE & $\chi^{2} / t$ & $P$-value & $\begin{array}{c}\text { Symptomatic } \\
\text { VTE }\end{array}$ & Non-VTE & $\chi^{2} / t$ & $P$-value \\
\hline Number & 24 & 696 & & & 39 & 1121 & & \\
\hline \multicolumn{9}{|c|}{ Pre-operative laboratory: } \\
\hline $\mathrm{PT}[\mathrm{s}]$ & $12.19 \pm 3.04$ & $11.81 \pm 1.16$ & 1.448 & 0.148 & $12.04 \pm 2.36$ & $11.67 \pm 1.29$ & 1.697 & 0.090 \\
\hline INR & $1.09 \pm 0.27$ & $1.04 \pm 0.42$ & 0.841 & 0.409 & $1.14 \pm 0.33$ & $1.09 \pm 0.25$ & 1.213 & 0.225 \\
\hline APTT [s] & $28.21 \pm 5.23$ & $26.73 \pm 6.78$ & 1.295 & 0.208 & $27.68 \pm 5.46$ & $26.32 \pm 5.93$ & 1.411 & 0.159 \\
\hline Fbg & $2.73 \pm 0.70$ & $3.05 \pm 0.70$ & 0.196 & 0.046 & $2.83 \pm 0.67$ & $3.09 \pm 0.81$ & 1.981 & 0.048 \\
\hline $\mathrm{Hgb}[\mathrm{g} / \mathrm{dl}]$ & $133.13 \pm 13.60$ & $130.89 \pm 14.33$ & 0.776 & 0.445 & $130.47 \pm 13.87$ & $129.76 \pm 13.46$ & 0.324 & 0.746 \\
\hline Hct (\%) & $39.59 \pm 3.72$ & $38.95 \pm 4.96$ & 0.670 & 0.503 & $38.80 \pm 4.08$ & $37.97 \pm 3.95$ & 1.289 & 0.198 \\
\hline Plt [per $\mathrm{mm}^{3}$ ] & $209.96 \pm 61.31$ & $217.84 \pm 60.67$ & 0.625 & 0.532 & $205.73 \pm 64.59$ & $212.64 \pm 66.67$ & 0.637 & 0.524 \\
\hline \multicolumn{9}{|l|}{ D-dimer, $n$ : } \\
\hline Normal & 16 & 428 & 0.273 & 0.602 & 25 & 754 & 0.029 & 0.866 \\
\hline Abnormal & 8 & 268 & & & 14 & 376 & & \\
\hline \multicolumn{9}{|l|}{ Premedication, $n$ : } \\
\hline Aspirin & 2 & 20 & 0.855 & 0.355 & 4 & 43 & 2.516 & 0.113 \\
\hline $\begin{array}{l}\text { Lipid-lowering } \\
\text { medicine }\end{array}$ & 1 & 23 & 0.121 & 0.729 & 4 & 51 & 1.601 & 0.206 \\
\hline
\end{tabular}

PT - prothrombin time, INR - international normalized ratio, APTT - activated partial thromboplastin time, Fbg - fibrinogen, Hgb hemoglobin, Hct - hematocrit, Plt - platelets, TXA - tranexamic acid.

Table V. Univariate analysis of type and number of complications between venous thromboembolism (VTE) and non-VTE patients

\begin{tabular}{|c|c|c|c|c|c|c|c|c|}
\hline \multirow[t]{2}{*}{ Indicators } & \multicolumn{4}{|c|}{ TXA } & \multicolumn{4}{|c|}{ Placebo } \\
\hline & $\begin{array}{l}\text { Symptomatic } \\
\text { VTE }\end{array}$ & Non-VTE & $\chi^{2} / t$ & $P$-value & $\begin{array}{l}\text { Symptomatic } \\
\text { VTE }\end{array}$ & Non-VTE & $\chi^{2} / t$ & $P$-value \\
\hline Number & 24 & 696 & & & 39 & 1121 & & \\
\hline \multicolumn{9}{|l|}{ Type of complication*, $n$ : } \\
\hline Hypertension & 13 & 383 & 0.018 & 0.894 & 16 & 544 & 0.576 & 0.448 \\
\hline Diabetes & 4 & 123 & 0.022 & 0.882 & 6 & 201 & 0.038 & 0.845 \\
\hline Cerebrovascular disease & 5 & 66 & 2.216 & 0.137 & 5 & 188 & 0.187 & 0.665 \\
\hline Arrhythmia & 1 & 23 & 0.119 & 0.729 & 1 & 42 & 0.002 & 0.963 \\
\hline Hyperlipidemia & 2 & 22 & 0.656 & 0.418 & 1 & 47 & 0.009 & 0.926 \\
\hline History of malignancy & 2 & 13 & 2.130 & 0.144 & 2 & 24 & 0.474 & 0.491 \\
\hline \multicolumn{9}{|l|}{ Anemia $[\mathrm{g} / \mathrm{l}]$ : } \\
\hline$<120$ & 5 & 123 & 0.016 & 0.899 & 7 & 221 & 0.005 & 0.946 \\
\hline$\geq 120$ & 19 & 573 & & & 32 & 900 & & \\
\hline \multicolumn{9}{|l|}{ Number of complications, $n$ : } \\
\hline $0-1$ & 13 & 485 & 1.781 & 0.182 & 22 & 729 & 0.879 & 0.349 \\
\hline$\geq 2$ & 11 & 211 & & & 17 & 392 & & \\
\hline
\end{tabular}

TXA - tranexamic acid. *Not all cases were included. 
Table VI. Univariate analysis of surgery-related parameters between venous thromboembolism (VTE) and non-VTE patients

\begin{tabular}{|c|c|c|c|c|c|c|c|c|}
\hline \multirow[t]{2}{*}{ Indicators } & \multicolumn{4}{|c|}{ TXA } & \multicolumn{4}{|c|}{ Placebo } \\
\hline & $\begin{array}{c}\text { Symptomatic } \\
\text { VTE }\end{array}$ & Non-VTE & $\chi^{2} / t$ & $P$-value & $\begin{array}{c}\text { Symptomatic } \\
\text { VTE }\end{array}$ & Non-VTE & $\chi^{2} / t$ & $P$-value \\
\hline Number & 24 & 696 & & & 39 & 1121 & & \\
\hline \multicolumn{9}{|l|}{ Anesthesia, $n$ : } \\
\hline $\mathrm{GA}$ & 19 & 588 & 0.175 & 0.675 & 35 & 924 & 0.944 & 0.331 \\
\hline Non-GA & 5 & 108 & & & 4 & 197 & & \\
\hline \multicolumn{9}{|l|}{ Surgery, $n$ : } \\
\hline Unilateral TKA & 14 & 550 & 4.696 & 0.030 & 19 & 754 & 5.025 & 0.025 \\
\hline Bilateral TKA & 10 & 146 & & & 20 & 367 & & \\
\hline \multicolumn{9}{|l|}{ Drainage, $n$ : } \\
\hline Yes & 22 & 686 & 3.182 & 0.074 & 36 & 1088 & 1.468 & 0.226 \\
\hline No & 2 & 10 & & & 3 & 33 & & \\
\hline \multicolumn{9}{|l|}{ Surgeon, $n$ : } \\
\hline A & 6 & 243 & 5.176 & 0.16 & 6 & 243 & 6.318 & 0.097 \\
\hline B & 12 & 215 & & & 12 & 215 & & \\
\hline C & 3 & 180 & & & 3 & 180 & & \\
\hline D & 3 & 58 & & & 3 & 58 & & \\
\hline
\end{tabular}

TKA - total knee arthroplasty, GA - general anesthesia, TXA - tranexamic acid.

Table VII. Multi-variate analysis of parameters between venous thromboembolism (VTE) and non-VTE patients

\begin{tabular}{|c|c|c|c|c|c|c|c|c|}
\hline \multirow[t]{2}{*}{ Indicators } & \multirow[t]{2}{*}{$B$} & \multirow[t]{2}{*}{ S.E. } & \multirow[t]{2}{*}{ Wald } & \multirow[t]{2}{*}{$\mathrm{d} f$} & \multirow[t]{2}{*}{ OR } & \multicolumn{2}{|c|}{$95 \% \mathrm{Cl}$} & \multirow[t]{2}{*}{$P$-value } \\
\hline & & & & & & LL & UL & \\
\hline Surgery & 1.284 & 0.431 & 8.864 & 1 & 3.612 & 1.551 & 8.41 & 0.003 \\
\hline BMI & -1.548 & 0.558 & 7.686 & 1 & 0.213 & 0.071 & 0.635 & 0.006 \\
\hline Fbg & 0.936 & 0.437 & 4.59 & 1 & 2.55 & 1.803 & 6.003 & 0.032 \\
\hline
\end{tabular}

$B M I$ - body mass index, Fbg - fibrinogen, OR - odds ratio, LL - lower limit, UL - upper limit.

$0.4 \%$, while the incidence was $0.5 \%$ in the group not using TXA. In addition, the majority of publications showed that TXA has an acceptable safety profile without increased risk of VTE [12, 27-31]. Our study found that compared with the historical control group, the incidence of symptomatic venous thrombosis did not increase significantly after using TXA. We believe that after using TXA, TKA in the conventional prevention of anticoagulation did not increase the risk of postoperative symptomatic VTE. Meanwhile, conventional routine lower limb vein imaging was not necessary for screening DVT.

The increase of Fbg was an independent risk factor, since Fbg was mainly involved in the coagulation process, and it has been reported as an independent risk factor for coronary heart disease [6]. The increase of plasma Fbg synthesis would lead to increased plasma Fbg levels, enhanced coagu- lation and formation of thrombosis [32]. In accord with these studies, our research showed a similar result that increased Fbg was significantly related to VTE. On the other hand, we found that BMI lower than $25 \mathrm{~kg} / \mathrm{m}^{2}$ was a protective factor for symptomatic VTE, and several reports have also confirmed this finding [33, 34]. Moreover, extension of surgery, especially extension due to the bilateral TKA when compared with unilateral, was an independent risk factor for postoperative TKA [35]. Thus, prediction of VTE risk and stratification of patients was an important step in the future. There are several main aspects necessary to reduce the risk of symptomatic VTE in the case of TXA.

Firstly, according to the preoperative conventional color Doppler ultrasound screening of deep vein thrombosis, TXA should not be used in the operation if the patient had a positive result. 
Secondly, with postoperative Wells score, timely screening of asymptomatic deep vein thrombosis, as well as timely treatment should be paid attention to. Lastly, physical prevention and early functional exercise were necessary.

This research had several limitations, mainly because the patients in our study and in historical research underwent different methods in using TXA, and were treated with different surgeons. Moreover, the final judgment of symptomatic VTE was based on the doctor's comprehensive consideration, and the judgments from different doctors would misguide the results. However, the VTE was judged according to the Wells score, so the study result was still reliable. Moreover, as the morbidity of symptomatic VTE was too low, its independent risk factor still needed a larger sample to analyze the result.

In conclusion, TXA appears to be a safe and efficacious medicine in TKA patients who are at high risk for VTE. Our study suggested that high BMI, low Fbg and bilateral simultaneous surgery might act as independent risk factors for VTE. For further safety evaluation, we need methods and procedures which are as uniform as possible in large-scale trials.

\section{Conflict of interest}

The authors declare no conflict of interest.

\section{References}

1. Chaudhry H, Bhandari M. Cochrane in CORR (®): Continuous passive motion following total knee arthroplasty in people with arthritis (review). Clin Orthop Relat Res 2015; 473: 3348-54.

2. Collis RE, Collins PW. Haemostatic management of obstetric haemorrhage. Anaesthesia 2015; 70 Suppl 1: 7886, e27-8.

3. Sassoon A, Nam D, Nunley R, Barrack R. Systematic review of patient-specific instrumentation in total knee arthroplasty: new but not improved. Clin Orthop Relat Res 2015; 473: 151-8.

4. Kurtz SM, Ong KL, Lau E, Bozic KJ. Impact of the economic downturn on total joint replacement demand in the United States: updated projections to 2021. J Bone Joint Surg Am 2014; 96: 624-30.

5. Fatic N, Nikolic A, Vukmirovic M, et al. Blood groups and acute aortic dissection type III. Arch Med Sci 2017; 13: 597-600.

6. Liu Y, Meng F, Yang G, Kong L, Shen Y. Comparison of intra-articular versus intravenous application of tranexamic acid in total knee arthroplasty: a meta-analysis of randomized controlled trials. Arch Med Sci 2017; 13: $533-40$.

7. Ilincic B, Stokic E, Stosic Z, et al. Vitamin D status and circulating biomarkers of endothelial dysfunction and inflammation in non-diabetic obese individuals: a pilot study. Arch Med Sci 2017; 13: 53-60.

8. Erem C, Kuzu UB, Deger O, Can G. Prevalence of gestational diabetes mellitus and associated risk factors in Turkish women: the Trabzon GDM Study. Arch Med Sci 2015; 11: 724-35.
9. Dimitrov BD, Bahchevanov KM, Atanassova PA, et al. Metabolic syndrome severity score: range and associations with cardiovascular risk factors. Arch Med Sci Atheroscler Dis 2016; 1: 90-7.

10. Falck-Ytter Y, Francis CW, Johanson NA, et al. Prevention of VTE in orthopedic surgery patients: Antithrombotic Therapy and Prevention of Thrombosis, 9th ed: American College of Chest Physicians Evidence-Based Clinical Practice Guidelines. Chest 2012; 141 (2 Suppl): e278S$325 \mathrm{~S}$.

11. Mont MA, Jacobs JJ. AAOS clinical practice guideline: preventing venous thromboembolic disease in patients undergoing elective hip and knee arthroplasty. J Am Acad Orthop Surg 2011; 19: 777-8.

12. Yang ZG, Chen WP, Wu LD. Effectiveness and safety of tranexamic acid in reducing blood loss in total knee arthroplasty: a meta-analysis. J Bone Joint Surg Am 2012; 94: 1153-9.

13. Parratte S, Pagnano MW. Instability after total knee arthroplasty. J Bone Joint Surg Am 2008; 90: 184-94.

14. Tengborn L, Blomback M, Berntorp E. Tranexamic acid - an old drug still going strong and making a revival. Thromb Res 2015; 135: 231-42.

15. Kelley TC, Tucker KK, Adams MJ, Dalury DF. Use of tranexamic acid results in decreased blood loss and decreased transfusions in patients undergoing staged bilateral total knee arthroplasty. Transfusion 2014; 54 : 26-30.

16. Gomez-Barrena E, Ortega-Andreu M, Padilla-Eguiluz NG, Perez-Chrzanowska H, Figueredo-Zalve R. Topical intraarticular compared with intravenous tranexamic acid to reduce blood loss in primary total knee replacement: a double-blind, randomized, controlled, noninferiority clinical trial. J Bone Joint Surg Am 2014; 96: 1937-44.

17. Kim TK, Chang CB, Koh IJ. Practical issues for the use of tranexamic acid in total knee arthroplasty: a systematic review. Knee Surg Sports Traumatol Arthrosc 2014; 22: 1849-58.

18. Alshryda S, Sarda P, Sukeik M, Nargol A, Blenkinsopp J, Mason JM. Tranexamic acid in total knee replacement: a systematic review and meta-analysis. J Bone Joint Surg Br 2011; 93: 1577-85.

19. Shen PF, Hou WL, Chen JB, Wang B, Qu YX. Effectiveness and safety of tranexamic acid for total knee arthroplasty: a prospective randomized controlled trial. Med Sci Monit 2015; 21: 576-81.

20. Godier A, Roberts I, Hunt BJ. Tranexamic acid: less bleeding and less thrombosis? Crit Care 2012; 16: 135.

21. Vaishya R, Vijay V, Demesugh DM, Agarwal AK. Surgical approaches for total knee arthroplasty. J Clin Orthop Trauma 2016; 7: 71-9.

22. Yi J, Liu $H$, Zhang $M$, et al. Management of traumatic hemothorax by closed thoracic drainage using a central venous catheter. J Zhejiang Univ Sci B 2012; 13: 43-8.

23. Xie J, Ma J, Kang P, et al. Does tranexamic acid alter the risk of thromboembolism following primary total knee arthroplasty with sequential earlier anticoagulation? A large, single center, prospective cohort study of consecutive cases. Thromb Res 2015; 136: 234-8.

24. Bin Abd Razak HR, Soon AT, Dhanaraj ID, Tan AH. Incidence of clinically significant venous thromboembolic events in Asian patients undergoing total knee arthroplasty without anticoagulation. J Arthroplasty 2012; 27: 1128-32.

25. Januel JM, Chen G, Ruffieux C, et al. Symptomatic in-hospital deep vein thrombosis and pulmonary embolism following hip and knee arthroplasty among patients re- 
ceiving recommended prophylaxis: a systematic review. JAMA 2012; 307: 294-303.

26. Poeran J, Rasul R, Suzuki S, et al. Tranexamic acid use and postoperative outcomes in patients undergoing total hip or knee arthroplasty in the United States: retrospective analysis of effectiveness and safety. BMJ 2014; 349: g4829.

27. Zeng Y, Si HB, Shen B, et al. Intravenous combined with topical administration of tranexamic acid in primary total hip arthroplasty: a randomized controlled trial. Orthop Surg 2017; 9: 174-9.

28. Dahuja A, Dahuja G, Jaswal V, Sandhu K. A prospective study on role of tranexamic acid in reducing postoperative blood loss in total knee arthroplasty and its effect on coagulation profile. J Arthroplasty 2014; 29: 733-5.

29. Karam JA, Bloomfield MR, Dilorio TM, Irizarry AM, Sharkey PF. Evaluation of the efficacy and safety of tranexamic acid for reducing blood loss in bilateral total knee arthroplasty. J Arthroplasty 2014; 29: 501-3.

30. Tan J, Chen H, Liu Q, Chen C, Huang W. A meta-analysis of the effectiveness and safety of using tranexamic acid in primary unilateral total knee arthroplasty. J Surg Res 2013; 184: 880-7.

31. Zhang H, Chen J, Chen F, Que W. The effect of tranexamic acid on blood loss and use of blood products in total knee arthroplasty: a meta-analysis. Knee Surg Sports Traumatol Arthrosc 2012; 20: 1742-52.

32. Shlebak AA, Katsarou AD, Adams G, Fernando F. A novel mutation in exon 2 of FGB caused by c.221G $>T$ dagger substitution, predicting the replacement of the native Arginine at position 74 with a Leucine (p.Arg74Leu dagger) in a proband from a Kurdish family with dysfibrinogenaemia and familial venous and arterial thrombosis. J Thromb Thrombolysis 2017; 43: 263-70.

33. Colmorn LB, Ladelund S, Rasmussen S, Secher NJ. Risk of a venous thromboembolic episode due to caesarean section and BMI: a study in northern Denmark covering 2000-2010. J Obstet Gynaecol 2014; 34: 313-6.

34. Parkin L, Sweetland S, Balkwill A, et al. Body mass index, surgery, and risk of venous thromboembolism in middle-aged women: a cohort study. Circulation 2012; 125: 1897-904.

35. Nagase $\mathrm{Y}$, Yasunaga $\mathrm{H}$, Horiguchi $\mathrm{H}$, et al. Risk factors for pulmonary embolism and the effects of fondaparinux after total hip and knee arthroplasty: a retrospective observational study with use of a national database in Japan. J Bone Joint Surg Am 2011; 93: e146. 